\title{
Multiple Organ Dysfunction Syndrome Caused by Sepsis: Risk Factor Analysis
}

\author{
Guo-Dong Sun' \\ Yang Zhang ${ }^{2}$ \\ Shan-Shan $\mathrm{Mo}^{3}$ \\ Ming-Yan Zhao' \\ 'Department of Critical Care Medicine, \\ The First Affiliated Hospital of Harbin \\ Medical University, Harbin, I5000 I, \\ Heilongjiang Province, People's Republic \\ of China; 'Department of Nursing, \\ Central Hospital of Heilongjiang Province \\ Prison, Harbin, I5000I, Heilongjiang \\ Province, People's Republic of China; \\ ${ }^{3}$ Pharmacy Department of Heilongjiang \\ Sailors General Hospital, Harbin, I5000I, \\ Heilongjiang Province, People's Republic \\ of China
}

Purpose: To analyze the risk factors of multiple organ dysfunction syndromes (MODS) caused by sepsis.

Patients and Methods: A total of 180 patients with sepsis admitted to The First Affiliated Hospital of Harbin Medical University (No. 23, Post Street, Nangang District, Harbin 150001, Heilongjiang province, China) from July 2018 to June 2019 were selected and divided into a non-MODS group and a MODS group, with 90 cases in each group. Clinical data of the patients were retrospectively analyzed, and univariable and multivariable analyses were performed.

Results: The univariable analysis showed that there were no significant differences in terms of age, body temperature, heart rate, respiration, mean arterial pressure, RBC specific volume, blood sodium, serum kalium, and infection site $(\mathrm{P}>0.05)$. Whereas significant differences were found between the groups in terms of gender, arterial blood $\mathrm{pH}, \mathrm{WBC}$ count, Apache II score, blood glucose, creatinine, chronic medical history, surgery, and ventilator usage $(\mathrm{P}<0.05)$. The growth of bacterial culture, the increase of creatinine level, chronic diseases and Apache II score were discovered to have significant effects on the occurrence of MODS through the multivariable logistic regression analysis.

Conclusion: Bacterial culture, serum creatinine level, history of chronic disease and Apache II score may be risk factors of MODS in sepsis patients.

Keywords: sepsis, multiple organ dysfunction syndrome, risk factors, systemic inflammatory response syndrome, sepsis patients, multivariable logistic regression analysis

\section{Introduction}

Sepsis is a systemic inflammatory response syndrome (SIRS) caused by either infectious or non-infectious factors. ${ }^{1-3}$ It can easily develop into septic shock and multiple organ dysfunction syndromes (MODS) if not treated in a timely manner, and its fatality rate can be as high as $28-56 \%{ }^{4}$ Clinically, MODS can be categorized into Phase I immediate type and Phase II delayed type. To date, the preferred medical examination for MODS includes the examination of hemogram, blood, pathogenic bacteria and urine. ${ }^{5,6}$ Systemic inflammatory response syndrome may be viewed as the systemic expression of cytokine signals that normally function on an autocrine or paracrine level. Sepsis is defined as systemic inflammatory response syndrome caused by an infection. MODS may represent the end stage of severe systemic inflammatory response syndrome or sepsis. Many cells are involved, including endothelial cells and leukocytes and multiple proinflammatory and antiinflammatory mediators (cytokines, oxygen free radicals, coagulation factors, and so forth). Various pathophysiologic mechanisms have been postulated. The most
Correspondence: Ming-Yan Zhao Email shizhaomi0I47@I26.com 
popular theory is that the inflammatory process loses its autoregulatory capacity. ${ }^{5,6}$ Existing studies recognize that immune dysfunction caused by uncontrolled systemic inflammatory response is the main pathophysiological mechanism of sepsis, while the underlying pathogenesis is poorly understood. ${ }^{5}$ Involving multiple organs and pathophysiological systems, these diseases are closely related to the systemic inflammatory network, bacterial endomycin, inflammatory mediators, immune dysfunction, intestinal bacterial and endotoxin translocation, coagulation dysfunction, and gene polymorphism. The pathogenesis of sepsis needs further clarification. ${ }^{7}$ This study was undertaken with an attempt to further elucidate the risk factors related to MODS caused by sepsis, and to take targeted prevention and treatment measures.

\section{Patients and Methods}

\section{General Material}

A total of 180 patients presenting to The First Affiliated Hospital of Harbin Medical University (No. 23, Post Street, Nangang District, Harbin 150001, Heilongjiang province, China) due to sepsis from July 2018 to June 2019 were selected for this research. Among them, there were 113 males and 67 females, who aged between 18-79 years (mean, 41.23 \pm 7.27 ) years old. There were 117 cases of acute abdominal disease (including suppurative cholangitis, acute severe pancreatitis, etc.), 6 cases of systemic infection, 19 cases of multiple injuries, 22 cases of abdominal trauma, and 16 other cases. Patients who were admitted to the intensive care unit (ICU) and then left or died in the ICU were included, while those who died within 24 hours after being sent to the ICU were excluded. The primary infection in patients with sepsis and diseases distribution were observed. The studies involving human participants were reviewed and approved by First Affiliated Hospital of Harbin Medical University. The patients provided their written informed consent to participate in this study. This study has been carried out in accordance with The Code of Ethics of the World Medical Association (Declaration of Helsinki) for experiments involving humans.

\section{Diagnostic Criteria}

Sepsis is defined in accordance with the diagnostic criteria in the Guidelines for Emergency Treatment of Sepsis/ Septic Shock in China (2018) issued by the Emergency Physicians Branch of the Chinese Physicians Association.
When the sequential organ failure assessment (SOFA) score rises by over 2 points from baseline, it is considered as sepsis. See Table 1. The criteria for organ dysfunction lie with the MODS score developed by Marshall, a Canadian scholar. See Table 2.

\section{Methods}

Patients were equally divided into a non-MODS group and a MODS group means according to their conditions. MODS standard was interpreted by the kidney, lung, heart, blood, liver and brain. Each organ is associated with several indicators. For instance, creatinine is considered the indicator for kidney, respiration for lung, heart rate for heart, concentration for sodium ion, serum kalium ion and blood glucose the indicators for blood. Each clinical indicator of the patient was recorded, and the worst value of each indicator was input into the database.

\section{Predictor Variables}

(1) General items: gender, age, history of chronic diseases.

(2) Post-inoculation (HPI): body temperature, heart rate, respiration, mean arterial pressure, arterial blood $\mathrm{pH}$ value, infection site, red blood cell (RBC), white blood cell (WBC) count, APACHE II score, surgery, blood sodium, blood serum kalium, blood glucose, serum creatinine, bacteria growth, ventilator usage.

\section{Statistical Methods}

SPSS22.0 statistical software was used for univariable analysis. Measurement data were represented by $(\bar{x} \pm \mathrm{s})$ and the differences between groups were analyzed by $t$-test. Enumeration data were expressed as $\mathrm{n}(\%)$ and the differences between groups were analyzed by $X^{2}$ test. Logistic regression was used for multivariable analysis. $P<0.05$ was considered statistically significant.

\section{Results}

\section{Comparison of Measurement Index Between the Groups}

No statistically significant difference was found in terms of age, body temperature, heart rate, respiration, mean arterial pressure, RBC hematocrit, blood sodium, serum kalium between the two groups $(P>0.05)$. The arterial blood $\mathrm{pH}$ value, the WBC count, APACHE II score, blood glucose, and creatinine were statistically different between the groups $(P<0.05)$. See Table 3 for details. 
Table I SOFA Scoring Criteria

\begin{tabular}{|c|c|c|c|c|c|}
\hline \multirow[t]{2}{*}{ System } & \multicolumn{5}{|c|}{ Score/Points } \\
\hline & 0 & $\mathbf{I}$ & 2 & 3 & 4 \\
\hline $\begin{array}{l}\text { Respiratory system } \\
\mathrm{PaO}_{2} / \mathrm{FiO}_{2} \\
/ \mathrm{mmHg}(\mathrm{kPa})\end{array}$ & $\geq 400(53.3)$ & $<400(53.3)$ & $<300(40.0)$ & $\begin{array}{c}<200(26.7)+\text { Mechanical } \\
\text { ventilation }\end{array}$ & $\begin{array}{c}<100(13.3)+\text { Mechanical } \\
\text { ventilation }\end{array}$ \\
\hline $\begin{array}{l}\text { Coagulation system } \\
\text { Blood platelet/ } \\
\left(10^{3} \cdot \mu \mathrm{L}^{-1}\right)\end{array}$ & $\geq 150$ & $<150$ & $<100$ & $<50$ & $<20$ \\
\hline $\begin{array}{l}\text { Liver } \\
\text { Bilirubin / } \\
{\left[\mathrm{mg} \cdot \mathrm{dl}^{-1}\left(\mu \mathrm{mol} \cdot \mathrm{L}^{-1}\right)\right]}\end{array}$ & $<1.2(20)$ & $1.2-1.9(20-32)$ & $2.0-5.9(33-101)$ & $<6.0-11.9(102-204)$ & $\geq 12.0(204)$ \\
\hline $\begin{array}{l}\text { Cardiovascular } \\
\text { system }\end{array}$ & $M A P \geq 70 \mathrm{mmHg}$ & $\mathrm{MAP}<70 \mathrm{mmHg}$ & $\begin{array}{c}\text { Dopamine }<5 \text { or } \\
\text { dobutamine (any } \\
\text { dose) }\end{array}$ & $\begin{array}{c}\text { Dopamine } 5.1-15.0 \text { or } \\
\text { epinephrine } \leq 0.1 \text { or } \\
\text { norepinephrine }>0.1\end{array}$ & $\begin{array}{l}\text { Dopamine }>15 \text { or adrenaline } \\
>0.1 \text { or norepinephrine }>0.1\end{array}$ \\
\hline $\begin{array}{l}\text { Central nerve } \\
\text { system (GCS) }\end{array}$ & 15 & $13-14$ & $10-12$ & $6-9$ & $<6$ \\
\hline $\begin{array}{l}\text { Kidney } \\
\text { Creatinine / } \\
{\left[\mathrm{mg} \cdot \mathrm{dl}^{-1}\left(\mu \mathrm{mol} \cdot \mathrm{L}^{-1}\right)\right]}\end{array}$ & $<1.2(110)$ & $\begin{array}{c}1.2-1.9(110- \\
170)\end{array}$ & $2.0-3.4(|7|-299)$ & $3.5-4.9(300-400)$ & $>4.9(440)$ \\
\hline $\begin{array}{l}\text { Urine Volume } \\
\left(\mathrm{mL} \cdot \mathrm{d}^{-1}\right)\end{array}$ & - & - & - & $<500$ & $<200$ \\
\hline
\end{tabular}

Table 2 MODS Score (Marshall Standard)

\begin{tabular}{|c|c|c|c|c|c|}
\hline \multirow[t]{2}{*}{ Organ } & \multicolumn{5}{|c|}{ Score } \\
\hline & $\mathbf{0}$ & $\mathbf{I}$ & 2 & 3 & 4 \\
\hline Respiratory system $\left(\mathrm{PaO}_{2} / \mathrm{FiO}_{2}\right)$ & $>300$ & $226-300$ & $|5|-225$ & $76-150$ & $\leq 75$ \\
\hline Kidney (Blood Crumol• $\mathrm{L}^{-1}$ ) & $\leq 100$ & $101-200$ & $20 I-350$ & $35 I-500$ & $>500$ \\
\hline Liver (hemobilirubin $\mu \mathrm{mol} \cdot \mathrm{L}^{-1}$ ) & $\leq 20$ & $21-60$ & $61-120$ & $|2|-240$ & $>240$ \\
\hline Cardiovascular system $(\mathrm{PAR}=\mathrm{HR} \times \mathrm{CVP} / \mathrm{MAP})$ & $\leq 10.0$ & $10.1-15.0$ & $15.1-20.0$ & $20.1-30.0$ & $>30.0$ \\
\hline Blood (platelet count $10^{9} \cdot \mathrm{L}^{-1}$ ) & $>120$ & $81-120$ & $5 \mathrm{I}-80$ & $21-50$ & $\leq 20$ \\
\hline Nerve system (Glasgow Coma score) & 15 & $13-14$ & $10-12$ & 7-9 & $\leq 6$ \\
\hline
\end{tabular}

\section{Comparison of Enumeration Indexes Between the Groups}

There was no statistically significant difference between the two groups in the site of infection $(P>0.05)$, but significant differences were found in terms of frequencies of gender, history of chronic disease, surgery, bacterial culture and growth, and ventilator usage $(P<0.05)$. See Table 4 for details.

\section{Logistic Regression Analysis of Risk Factors for MODS in Sepsis Patients}

The univariable analysis preliminarily screened out gender, arterial blood $\mathrm{pH}$ value, the WBC count, APACHE II score, blood glucose, creatinine, chronic disease, bacterial culture growth, surgery, and ventilator usage, totaling 10 variables for binary logistic regression analysis. The result showed that the growth of bacterial culture, increased creatinine level, combined chronic diseases, a higher score of APACHE II are risk factors for MODS occurrence. See Table 5 for details.

\section{Site Composition of Primary Infection in Patients with Sepsis}

Compared with the incidence of respiratory tract infection, the incidence of digestive tract, abdominal cavity, 
Table 3 Comparison of Measurement Data Between the Two Groups ( $\bar{x} \pm \mathrm{s}$ )

\begin{tabular}{|c|c|c|c|}
\hline Observation Index & MODS Group $(n=90)$ & Non-MODS Group $(n=90)$ & $\mathbf{P}$ \\
\hline Age (year old) & $46.04 \pm 17.42$ & $43.83 \pm|5.2|$ & 0.366 \\
\hline Body temperature $\left({ }^{\circ} \mathrm{C}\right)$ & $38.53 \pm 0.91$ & $38.58 \pm 0.94$ & 0.717 \\
\hline Heart rate (times/min) & $1 \mid 3.80 \pm 18.07$ & $110.92 \pm 16.81$ & 0.269 \\
\hline Respiration (times/min) & $29.44 \pm 6.42$ & $27.84 \pm 5.05$ & 0.065 \\
\hline MAP (mmHg) & $88.15 \pm 19.35$ & $90.42 \pm 18.01$ & 0.416 \\
\hline Arterial blood $\mathrm{Ph}$ value & $8.42 \pm 0.23$ & $7.45 \pm 0.08$ & $<0.001$ \\
\hline RBC specific volume (\%) & $34.42 \pm 9.95$ & $36.76 \pm 9.28$ & 0.105 \\
\hline WBC count $\left(\times 10^{9} \cdot \mathrm{L}^{-1}\right)$ & $19.88 \pm 5.34$ & $|6.86 \pm 5.9|$ & $<0.001$ \\
\hline APACHE II Score (points) & $26.14 \pm 11.36$ & $16.13 \pm 6.86$ & $<0.001$ \\
\hline Blood sodium $\left(\mathrm{mmol} \cdot \mathrm{L}^{-1}\right)$ & $138.88 \pm 8.67$ & $138.05 \pm 7.1 \mid$ & 0.483 \\
\hline Serum kalium $\left(\mathrm{mmol}^{\circ} \mathrm{L}^{-1}\right)$ & $5.38 \pm 0.92$ & $5.35 \pm 0.64$ & 0.799 \\
\hline Blood glucose $\left(\mathrm{mmol} \cdot \mathrm{L}^{-1}\right)$ & $21.33 \pm 6.30$ & $10.65 \pm 3.92$ & $<0.001$ \\
\hline Creatinine $\left(\mu \mathrm{mol} \cdot \mathrm{L}^{-1}\right)$ & $185.46 \pm 235.16$ & $84.03 \pm 94.51$ & $<0.001$ \\
\hline
\end{tabular}

Table 4 Comparison of Enumeration Data Between the Two Groups [n (\%)]

\begin{tabular}{|l|c|c|c|}
\hline Observation Index & $\begin{array}{c}\text { MODS } \\
\text { Group } \\
(\mathbf{n}=\mathbf{9 0})\end{array}$ & $\begin{array}{c}\text { Non- } \\
\text { MODS } \\
\text { Group } \\
(\mathbf{n}=\mathbf{9 0})\end{array}$ & $\boldsymbol{P}$ \\
\hline $\begin{array}{l}\text { Gender (Male/Female) } \\
\begin{array}{l}\text { History of chronic disease } \\
\text { (Yes/No) }\end{array}\end{array}$ & $\begin{array}{l}71 / 19 \\
\text { Infection site (Respiration } \\
\text { system/Other than }\end{array}$ & $\begin{array}{l}58 / 32 \\
17 / 73\end{array}$ & 0.032 \\
$\begin{array}{l}\text { Respiration system) } \\
\text { Surgery (Surgery/Non- }\end{array}$ & $39 / 51$ & $81 / 9$ & 0.002 \\
$\begin{array}{l}\text { surgery) } \\
\text { Bacteria culture growth (Yes/ }\end{array}$ & $35 / 55$ & $53 / 37$ & 0.007 \\
$\begin{array}{l}\text { No) } \\
\text { Ventilator usage (Applied/Not }\end{array}$ & $76 / 14$ & $85 / 5$ & 0.029 \\
applied) & & 0.025 \\
\hline
\end{tabular}

nervous system and other infections was significantly lower $\left(X^{2}=34.844, P<0.05\right)$. See Figure 1 for details.

\section{Disease Distribution in the Two Groups}

The diseases of the patients are mainly diffuse peritonitis, pancreatitis, hepatobiliary diseases, multiple injuries, intestinal obstruction, chest diseases, limb diseases, etc. No significant difference was observed in the disease distribution between the two groups $(P>0.05)$. See Figure 2 for details.

\section{Discussion}

Sepsis serves as the organ dysfunction syndrome caused by the imbalance of the human body's response to infection. ${ }^{8}$ After infection, inflammatory response cells are activated by bacterial toxins and will release inflammatory mediators such as interleukin-6 (IL-6), interleukin-1 (IL-1) and tumor necrosis factor- $\alpha$ (TNF- $\alpha$ ), triggering systemic or local inflammatory responses. ${ }^{9-11}$ Its clinical manifestations include changes in mental state, shortness of breath, palpitation, fever, chills and other symptoms, and in severe cases, MODS will develop. ${ }^{12}$ MODS refers to the clinical syndrome in which at least two systems or organs suffer from simultaneous or sequential dysfunction during major surgery, infection, shock, poisoning and severe trauma, thus undermining the stability of the internal environment. ${ }^{13-15}$ Early Goal-Directed Therapy (EGDT) regimen, early monitoring of risk factors and active fluid resuscitation can reduce the incidence and mortality of MODS, and plays a key role in early control of sepsis. ${ }^{16}$

Table 5 Logistic Regression Analysis of Risk Factors for MODS in Sepsis Patients

\begin{tabular}{|l|c|c|c|c|}
\hline Factors & Estimated Parameter & P value & OR Value & $\mathbf{9 5 \% ~ C I}$ \\
\hline Bacterial culture growth & -1.776 & 0.032 & 0.275 & $0.045,0.787$ \\
Increased creatinine level & 0.061 & $<0.001$ & 1.062 & $1.028,1.075$ \\
Combined chronic diseases & -1.758 & 0.029 & 0.204 & $0.049,0.768$ \\
Increased APACHE II score & 0.339 & $<0.001$ & 1.367 & $1.132,1.394$ \\
\hline
\end{tabular}




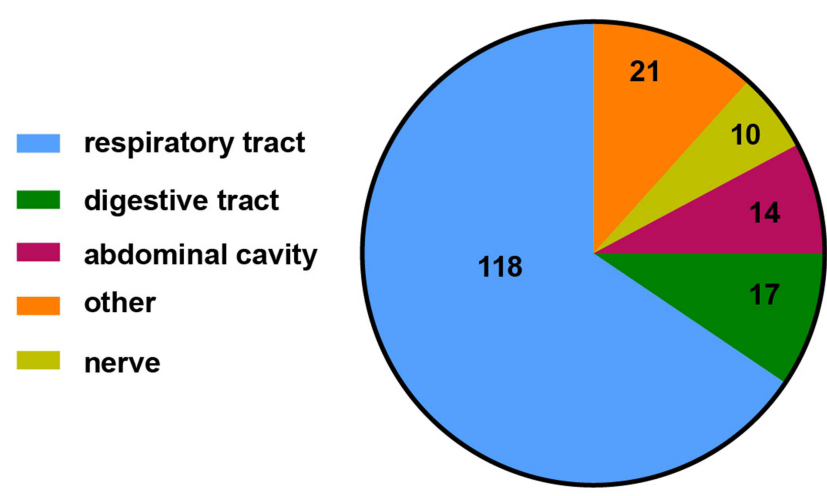

Figure I Site composition of primary infection in patients with sepsis.

The univariable analysis of this research showed that the two groups of patients had significant differences in gender, arterial blood $\mathrm{pH}$ value, WBC count, APACHE II score, blood glucose, serum creatinine, chronic disease, bacterial culture growth, surgery, ventilation treatment. Additionally, it is documented that patients with sepsis caused by shock, infection, trauma and other factors will have pathophysiological changes in their circulatory, respiratory and nervous systems, including tissue and organ ischemia and hypoxia, renal function decline, electrolyte disturbance, shortness of breath, blood pressure drop, and acid-base imbalance. ${ }^{17}$ On account of these, MODS and even death may arise if early symptoms are not treated in time.

The multivariable logistic stepwise regression analysis showed that the growth of bacterial culture, increased creatinine level, combined chronic diseases, a higher score of APACHE II are risk factors for the occurrence of MODS. As a vital index for evaluating sepsis patients, APACHE II score reflects the association between the body's physiological disorders and the severity of sepsis, which is positively correlated with MODS. ${ }^{18}$ Moreover, it has been pointed out by a prior trial that patients with sepsis combined with cardiopulmonary diseases, diabetes, hypertension and other chronic diseases have a higher risk of developing MODS than others. ${ }^{19}$ Serum creatinine is also an important indicator to observe the development of sepsis. Systemic inflammatory reactions owing to infection can easily cause changes in the circulatory system. It in turn dilates blood vessels, slows down blood flow and lowers blood pressure, and subsequently further decreases renal blood flow, impairs renal function and increases serum creatinine. Our study demonstrated that serum creatinine in the MODS group was significantly higher than that in the non-MODS group. Taken together, early protection of renal function and improvement of microcirculation are of paramount importance for the treatment of MODS. $^{20}$

Hence, we suggest that gender, arterial blood $\mathrm{pH}$ value, the WBC count, APACHE II score, blood glucose, serum creatinine, chronic disease, surgery, bacterial growth, ventilator usage and other factors were relevant to the development of MODS in patients with sepsis in the Emergency Department in The First Affiliated Hospital of Harbin Medical University (No. 23, Post Street, Nangang District, Harbin 150001, Heilongjiang province, China.). Among them, bacteria culture growth, increased creatinine level, combined chronic diseases, a higher score of APACHE II appear to to be risk factors for the occurrence of MODS. Therefore, early monitoring of these factors and timely control measures can improve the

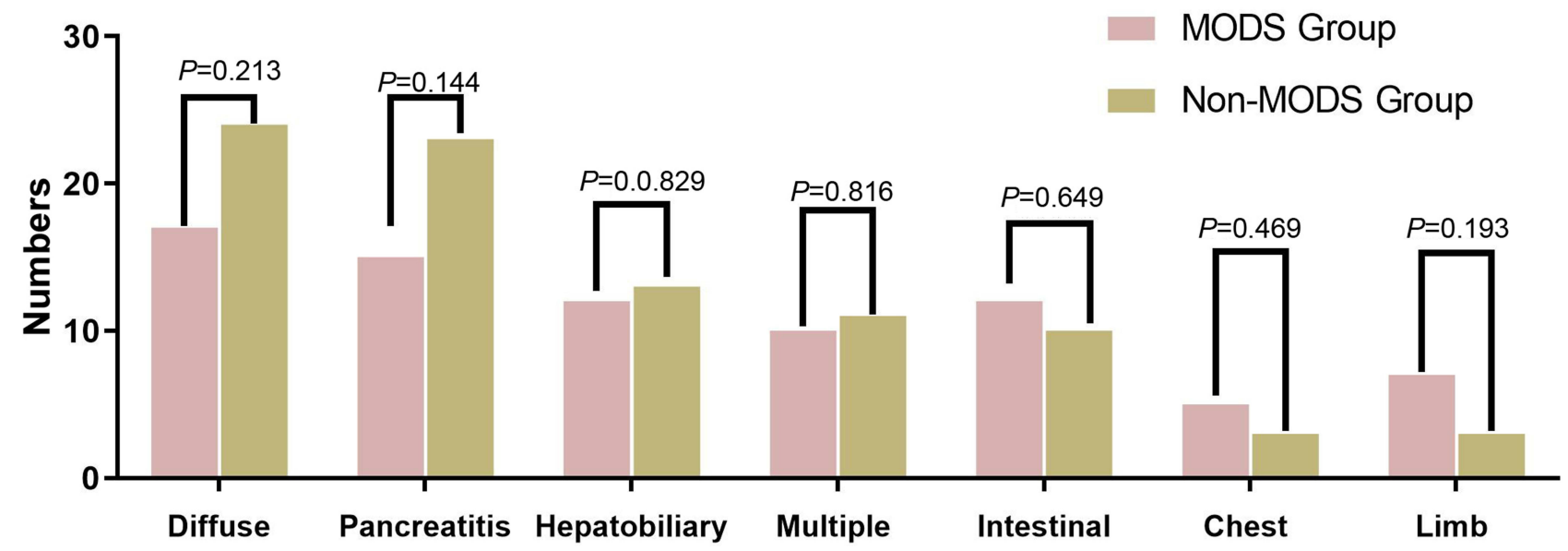

Figure 2 Disease distribution. 
cure rate and reduce the fatality rate of sepsis patients. Moreover, the confounding and omitted variables of the results were critical and should be emphasized in future. Meanwhile, a multivariable model with a less selective set of explanatory variables should be performed in future studies.

Thus, we concluded that Bacterial culture, serum creatinine level, history of chronic disease and Apache II score might be risk factors of MODS in sepsis patients.

\section{Disclosure}

The authors report no conflicts of interest in this work.

\section{References}

1. Srouji LS, Moore-Clingenpeel M, Hensley J, et al. shock severity modifies associations between RBC transfusion in the first 48 hours of sepsis onset and the duration of organ dysfunction in critically ill septic children. Pediatr Crit Care Med. 2020;21(8):e475-e484. doi:10. 1097/PCC.0000000000002338

2. Zhang Q, Shan F. The role of p38 mitogen-activated protein kinase signaling pathway in the sepsis with multiple organ dysfunction syndrome. Chin J Cell Biol. 2018. Available from: https://d.wanfang data.com.cn/periodical/xbswxzz201802018. Accessed October 19, 2021.

3. Bojana M, Roy H, Frédéric M, et al. Conservative management of pelvic sepsis with severe shock and multiple organ dysfunction syndrome after rubber-band ligation of internal haemorrhoids: surgery is not the only option. J Surg Case Rep. 2018;2018(8):8.

4. Ziesmann MT, Marshall JC. Multiple organ dysfunction: the defining syndrome of sepsis. Surg Infect (Larchmt). 2018;19(2):184-190. doi:10.1089/sur.2017.298

5. Drobatz KJ, Hopper K, Rozanski E, et al. Textbook of Small Animal Emergency Medicine || Systemic Inflammatory Response Syndrome, Sepsis, and Multiple Organ Dysfunction Syndrome. John Wiley \& Sons; 2018.

6. Zhang L, Zhang T, Bian K, Wu D. Clinical effect of CHVHF on severe sepsis complicated with multiple organ dysfunction syndrome and its effect on hemodynamics. Clin Res Pract. 2018. Available from: https://wenku.baidu.com/view/bce38cc2e3bd960590c69ec3d5bbf d0a7956d5ae?fr=xueshu. Accessed October 19, 2021.

7. Troia R, Giunti M, Goggs R. Plasma procalcitonin concentrations predict organ dysfunction and outcome in dogs with sepsis. BMC Vet Res. 2018;14(1):111. doi:10.1186/s12917-018-1427-y

8. Ramirez JA. A continuum of disease from community-acquired pneumonia to multiple organ dysfunction syndrome. Univ Louisville J Respir Infect. 2018;2:4-6. doi:10.18297/jri/vol2/iss2/1/
9. Alcamo A, Pang D, Bashir D, et al. Role of damage-associated molecular patterns and uncontrolled inflammation in pediatric sepsis-induced multiple organ dysfunction syndrome. J Pediatr Intensive Care. 2019;08(01):025-031. doi:10.1055/s-0038-1675639

10. Gatica S, Eltit F, Santibanez J, et al. Expression suppression and activity inhibition of TRPM7 regulate cytokine production and multiple organ dysfunction syndrome during endotoxemia: a new target for sepsis. Curr Mol Med. 2019;19(8):547-559. doi:10.2174/1566524 019666190709181726

11. Kell DB, Pretorius E. To what extent are the terminal stages of sepsis, septic shock, systemic inflammatory response syndrome, and multiple organ dysfunction syndrome actually driven by a prion/amyloid form of fibrin? Semin Thromb Hemost. 2018;44(03):224-238. doi:10.1055/s-0037-1604108

12. Cheng Z, Abrams ST, Alhamdi Y, et al. Circulating histones are major mediators of multiple organ dysfunction syndrome in acute critical illnesses. Crit Care Med. 2019;47(8):e677-e684. doi:10.1097/ CCM.0000000000003839

13. Zhang YJ, Zhuo XA, Zhou XM, Dai WJ. Prognostic value of lactate/ albumin ratio in the elderly sepsis patients complicated with multiple organ dysfunction syndrome. Chin J Multiple Organ Dis Elder. 2018. Available from: https://d.wanfangdata.com.cn/periodical/ zhlndqgjbzz201804003. Accessed October 19, 2021.

14. Man-Xue M, Zhi-Guang WU, Jin-Li F, et al. Overview of Chinese medicine for treatment of sepsis with multiple organ dysfunction. J Guangzhou Univ Trad Chin Med. 2019.

15. Vallejos A, Olivares P, Gatica S, et al. Endotoxemia-induced endothelial fibrosis inhibition improves hypotension, tachycardia, multiple organ dysfunction syndrome, cytokine response, oxidative stress, and survival. Lab Investig. 2019;99(8):1173-1192.

16. Huang W, Qin S, Sun Y, et al. [Establishment of multiple organ dysfunction syndrome early warning score in patients with severe trauma and its clinical significance: a multicenter study]. Zhonghua W Zhong Bing Ji Jiu Yi Xue. 2018;30(1):41-46. Chinese.

17. Xie J, Yang F, Chen J, Wang W, Yi C, Bai X. Application of vacuum sealing drainage in treatment of open fractures and multiple organ dysfunction syndrome. J Trauma Surg. 2018. Available from: http:// qikan.cqvip.com/Qikan/Article/Detail?id=675978887\&from=Qikan_ Search_Index. Accessed October 19, 2021.

18. Uchida M, Abe T, Ono K, et al. Ulinastatin did not reduce mortality in elderly multiple organ failure patients: a retrospective observational study in a single center ICU. Acute Med Surg. 2018;5 (1):90-97. doi:10.1002/ams2.304

19. Wu D, Shi S, Zhang R, et al. Expression and clinical significance of the novel inhibitory cytokine IL-3S in patients with sepsis and multiple organ dysfunction syndrome. Chin J Emerg Med. 2019;28(2):175-180.

20. Zhang WF, Chen DM, Wu LQ, et al. Clinical effect of continuous blood purification in treatment of multiple organ dysfunction syndrome in neonates. Zhongguo Dang Dai Er Ke Za Zhi = Chinese Journal of Contemporary Pediatrics. 2020;22(1):31-36.
International Journal of General Medicine

\section{Publish your work in this journal}

The International Journal of General Medicine is an international, peer-reviewed open-access journal that focuses on general and internal medicine, pathogenesis, epidemiology, diagnosis, monitoring and treatment protocols. The journal is characterized by the rapid reporting of reviews, original research and clinical studies across all disease areas. The manuscript management system is completely online and includes a very quick and fair peer-review system, which is all easy to use. Visit http://www.dovepress.com/ testimonials.php to read real quotes from published authors. 